\section{BMJ Paediatrics Open}

\title{
Paediatric elbow fractures and public play spaces: adherence to standards for children's playground equipment and surfacing
}

\author{
Jennifer Smith (D) , ${ }^{1}$ Harpreet Chhina (D) , ${ }^{2}$ Pardeep Sidhu (D) , \\ Mariana Brussoni (D) , "1,3 lan Pike (D) , ",4 Anthony Cooper (D) ${ }^{2,5}$
}

To cite: Smith J, Chhina H, Sidhu P, et al. Paediatric elbow fractures and public play spaces: adherence to standards for children's playground equipment and surfacing BMJ Paediatrics Open 2021;5:e001125. doi:10.1136/ bmjpo-2021-001125

Received 26 April 2021 Accepted 5 September 2021

Check for updates

(C) Author(s) (or their employer(s)) 2021. Re-use permitted under CC BY-NC. No commercial re-use. See rights and permissions. Published by BMJ.

${ }^{1} \mathrm{BC}$ Injury Research and Prevention Unit, BC Children's Hospital, Vancouver, British Columbia, Canada

${ }^{2}$ Department of Orthopaedic Surgery, BC Children's Hospital, Vancouver, British Columbia, Canada

${ }^{3}$ Human Early Learning Partnership, School of Population and Public Health, The University of British Columbia Faculty of Medicine, Vancouver, British Columbia, Canada

${ }^{4}$ Department of Pediatrics, The University of British Columbia Faculty of Medicine, Vancouver, British Columbia, Canada ${ }^{5}$ Department of Orthopaedics, The University of British Columbia Faculty of Medicine, Vancouver, British Columbia, Canada

Correspondence to Ms Jennifer Smith; jsmith@ bcchr.ca

\section{ABSTRACT}

Background Supracondylar humerus fractures (SCHF) are the most common fractures sustained following a fall onto an outstretched hand among healthy children, and one of the leading causes of hospital admission and surgical intervention. The aim of this study was to examine SCHF occurring at public play spaces-particularly to determine whether or not the playground equipment implicated in injurious falls aligned with Canadian playground safety standards.

Methods Cases of children who attended the provincial paediatric orthopaedic clinic following SCHF at a public playground between April 2017 and October 2019 were included in the study. A research assistant visited each playground to measure the play structure type and dimensions, height of the equipment at the point from which the child fell and the type and depth of the surface material, and compare measurements to the 2016 safety standards. Child demographics and injury classification were also noted. Descriptive statistics were calculated and a scatterplot of fall height and surface depth was generated.

Results Forty-three sites, representing 47 SCHF cases (18 female, 29 male), were included in the final analysis. Fourteen children sustained type 1 fracture, 23 had type 2 fracture and the remaining 10 had type 3 fracture. Five children with type 2 fracture and all 10 children with type 3 fracture required surgery. The majority of sites had engineered wood fibre surfacing, with surfacing at 35 sites being less than $300 \mathrm{~mm}$ deep. Twenty-six play structures were upper body equipment (ie, monkey bars or similar), seven were track rides, five were rotating structures and the rest comprised a variety of classified and unclassified structures. Twenty-seven children fell from a height exceeding $2 \mathrm{~m}$.

Conclusions The majority of SCHF cases occurred at playgrounds with insufficient surface depth and/or noncompliant equipment. Upper body equipment, track rides and rotating play structures were of particular concern, as the children fell from heights exceeding the recommended standard, likely reflecting the degradation and compaction of the surfacing material over time.

\section{INTRODUCTION}

Risky play-challenging and exhilarating play that carries an inherent risk of physical injury — is an essential part of a child's healthy

\section{What is known about the subject?}

Elbow fractures are common among children who fall from play equipment, and represent one of the leading causes of hospital admission and surgical intervention.

- While majority of these injuries are not life threatening, elbow fractures requiring surgical intervention can be costly, distressing and carry the risk of longterm complications.

- Fall heights exceeding $2 \mathrm{~m}$ are more likely to result in severe injuries; standard heights of play structures are often set to reflect this limit.

\section{What this study adds?}

- Most elbow fracture cases occurred at playgrounds with surface depth below the $300 \mathrm{~mm}$ threshold triggering recommended maintenance (35/43 sites).

- Upper body equipment, track rides and rotating play structures were of particular concern.

- The majority of children fell from heights exceeding $2 \mathrm{~m}$, likely reflecting the degradation and compaction of the surfacing material over time.

physical, social and emotional development. ${ }^{12}$ Playgrounds with a variety of equipment that children can climb, spin around on, slide down and swing from potentially afford children opportunities to challenge their abilities, but also expose them to a risk of falling. Supracondylar humerus fractures (SCHF) are the most common fractures sustained following a fall onto an outstretched hand among healthy children, and one of the leading causes of hospital admission and surgical intervention. ${ }^{4}$ Between 2007 and 2014 in British Columbia, an annual average of 151 children aged 5-14 years visited the emergency department at BC Children's Hospital, and 74 were admitted to hospital throughout the province, following an elbow/ 
forearm fracture resulting from a fall from playground equipment. ${ }^{5}$ While the majority of these injuries are not severe or life threatening, ${ }^{7}$ SCHF requiring surgical intervention can be costly, distressing and carry the risk of long-term complications. ${ }^{8}$ Preventing the most serious of these injuries is therefore a desirable goal.

While playground equipment safety standards vary between countries, the literature indicates that fall heights exceeding $2 \mathrm{~m}$ are more likely to result in severe injuries to the limbs and head, and therefore maximum heights are set to reflect this limit. ${ }^{9}$ In Canada, such standards are developed by the Canadian Standards Association (CSA). These standards are voluntary, yet many municipal governments and school boards have adopted the standards as policy and choose playground equipment that is compliant with the relevant standard. There has been criticism of potential conflicts of interest among the membership of the CSA, and concerns regarding the over-reach of standards to regulate children's play behaviours have questioned the wisdom of adopting standards beyond engineering-related issues. ${ }^{10-12}$ There is some evidence that compliance with the standards specific to equipment engineering-related issues can reduce injuries. Studies examining the effect of replacing outdated play equipment with CSA-compliant structures at elementary schools in Toronto, Canada, showed that injury rates in the intervention schools dropped and, although the drop itself was not significant, the relationship between socioeconomic status of the schools and injury was no longer statistically significant following the playground upgrades. ${ }^{10} 13$

The aim of this study was to examine the potential causes or contributing circumstances associated with SCHF occurring at public play spaces-particularly to determine whether or not the playground equipment implicated in injurious falls aligned with CSA standards. Findings of this study can help guide prevention policies and inform the decisions around the design of public playgrounds, equipment selection, surfacing and maintenance of these spaces.

\section{METHODS}

Children aged 6-12 years who sustained SCHF between April 2017 and October 2019 were recruited from the paediatric orthopaedic clinic at BC Children's Hospital in Vancouver, British Columbia, Canada, which serves the entire province. Parents of eligible children were approached for recruitment and consent during their regular postinjury clinic appointments. Children from this cohort who sustained their injury playing in a public playground within a $50 \mathrm{~km}$ radius of the clinic were included in the study and the site was visited by a research assistant. Site of injury and exact play structure were identified either from the geotagged photographs of play structures taken by the children or as identified by the children on Google Maps at the time of recruitment into the study. At the start of the study, recruited children and families were required to go back to the site of injury to take photographs of the play structures involved in the fall and participate in multiple research visits at the 3,6 and 12-week postinjury appointments at the orthopaedic clinic. However, this was found to be a rate-limiting step for recruitment. Hence, the methodology was revised to allow for a single interview with the children to identify the exact play structure using Google Maps' satellite view. Details of the modifications in the study methodology are published separately. ${ }^{14}$

Because it was not practical to send a research assistant to measure play structures located on private property, only injuries that occurred at a public playground located in a park or at a public school were included in the present study. The play structure type and dimensions, height of the equipment at the point from which the child fell and the type and depth of the surface material were measured at each site and compared with the 2016 CSA standard, which was the most current at the time of the study (CAN/CSA-Z614-14; approved February 2015, revised September 2016) ${ }^{15}$ Age and sex of the child and fracture classification were also noted. Gartland 1 fractures (type 1) were classified as those with no displacement and treated with an above-elbow cast. ${ }^{16}$ Gartland 2 fractures (type 2) were classified as those with mild displacement and intact posterior cortex. These fractures were treated with closed reduction and taping or casting in the emergency department. Gartland 3 fractures (type 3 ) were classified as those with complete displacement, requiring either closed or open reduction and percutaneous pinning.

Site measurements and child demographics for each SCHF case were recorded and tabulated in Microsoft Excel. Descriptive statistics including mean, median, mode and range were calculated for child age, and reported with counts. A scatterplot of fall height and surface depth was generated for cases occurring on sites with engineered wood fibre (EWF) surfacing. EWF is defined as loose fill surfacing made of processed virgin wood, containing no twigs or leaves. ${ }^{15}$

\section{Patient and public involvement}

Patients or the public were not involved in the design, or conduct, or reporting, or dissemination plans of our research.

\section{RESULTS}

During phase 1 (the original methodology) from April 2017 to July 2018 there were 58 eligible study participants and 17 were recruited. For phase 2 (the revised methodology) between October 2018 and October 2019, there were 116 eligible participants and 47 who were recruited. Five cases were excluded as the play structure was on private property and therefore not eligible for a site visit by the research assistant. Forty-three sites, representing 47 SCHF cases (18 female, 29 male), were included in the final analysis. Fourteen children sustained type 1 


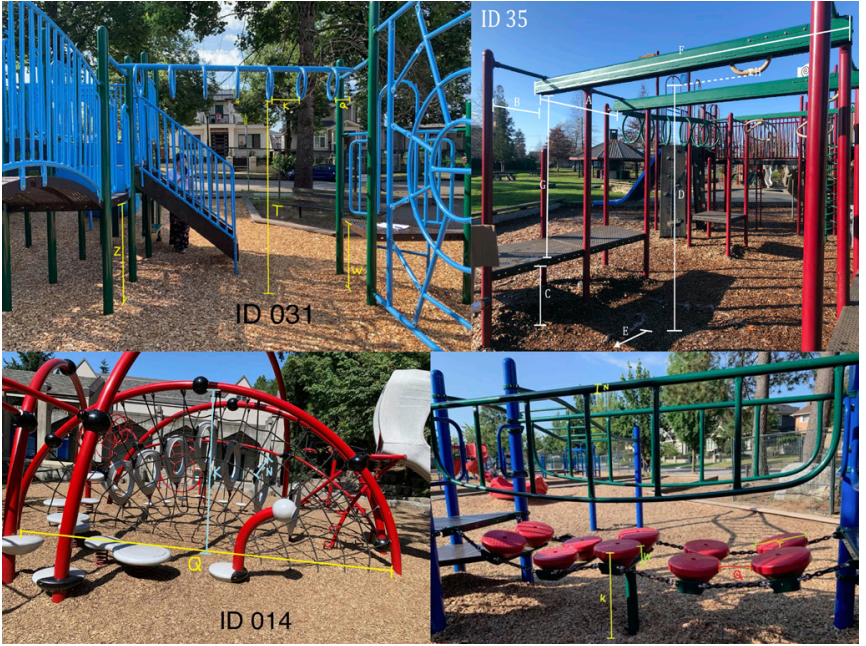

Figure 1 Examples of play structure types. Clockwise from top left: upper body structure, track ride, unclassified bridge and climbing net structure. The notations on the pictures were used by the research assistants to populate the data set in Excel.

fracture, 23 had type 2 fracture and the remaining 10 had type 3 fracture. Five children with type 2 fracture and all 10 children with type 3 fracture required surgery. The mean child age at the time of injury was 7.0 years (median age $=7$, mode $=6$, range from 5 to 10 years); those who were most seriously injured (type 3 ) were on average 6.8 years old while those with the least severe injury (type 1) were 7.3 years old.

Eighty-five per cent of the sites were school playgrounds; however, not all injuries occurred during school hours. Forty-two sites had EWF surfacing; three were rubber, one sand and one cement. Seven sites met the minimum CSA depth of $300 \mathrm{~mm}$, applicable to EWF and sand surfacing. It is important to note that depths less than $300 \mathrm{~mm}$ are not recommended by the CSA, but this does not mean that depths over $300 \mathrm{~mm}$ are considered safe, as impact attenuation can vary at a given depth and is specific to both the fall height and the surface material. ${ }^{15}$ Twenty-six play structures were upper body equipment (ie, monkey bars or similar), seven were track rides, five were rotating structures and the rest comprised a variety of classified and unclassified structures including climbers, swings, slides, sandbox, pyramid, climbing net structures, unclassified bridge and unclassified circular spinning structures (figure 1). Twenty-seven children fell from a height exceeding $2 \mathrm{~m}$, while fall height could not be determined in two cases. Figure 2 plots the injury severity by fall height and surface depth, showing that all but three sites were outside of the standard limits of these parameters. Table 1 summarises the child and site characteristics by play structure type.

Table 2 summarises the measurements of the three most commonly involved play equipment. The majority of falls were from upper body equipment $(n=26)$. Of these, three children with type 3 and type 2 fractures each required surgery. The severity of injury did not relate to the type of

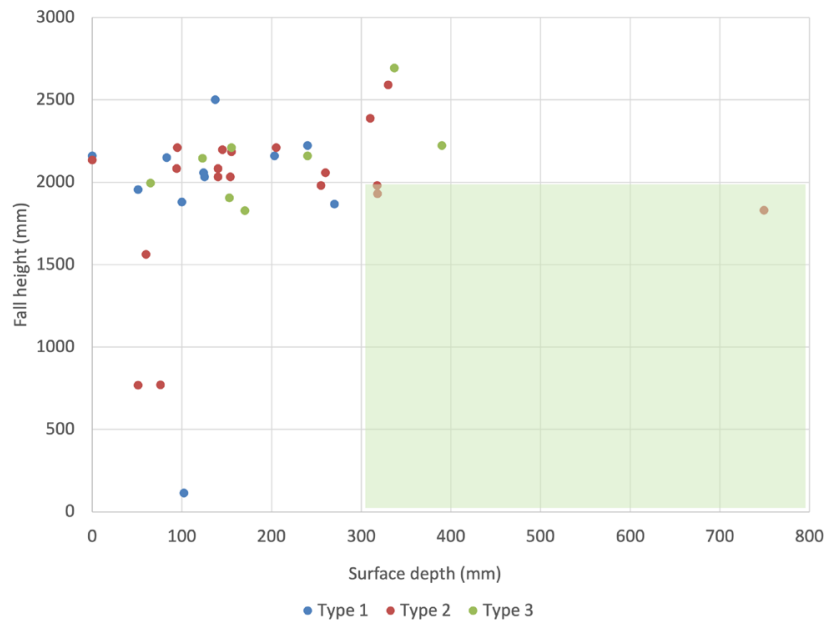

Figure 2 Injury severity by fall height and surface depth in millimetres. Fall height could not be determined in two cases and surface depth was not applicable or could not be measured precisely in seven cases; a total of nine cases were excluded from the figure. Green zone represents alignment with the Canadian Standards Association (CSA) standards, as applicable.

play structure, height of fall or surface depth. The mechanism of the fall was most commonly either from hanging on the handgrips or jumping to the handgrips from the platform. Eleven upper body structures exceeded the standard maximum height of $2.1 \mathrm{~m}$ and 16 structures exceeded the standard maximum distance between the platform and the handgrips. Eight upper body structures did not have fixed handgrips, rendering them exempt from the CSA standard of maximum distance between the grips, yet all were at least $80 \mathrm{~mm}$ over that maximum. The diameter of the handgrips of all but one upper body play structure met the standard.

The second most commonly involved play structure was a track ride $(n=7)$. Of the seven children injured, four sustained type 2 fracture and two had type 3 fracture. One child with a type 2 fracture and two children with type 3 fracture received surgery. Six out of seven track rides exceeded the maximum CSA height of $1950 \mathrm{~mm}$. The depth of the surfacing below every track ride was less than $300 \mathrm{~mm}$; at four sites, it was less than half the recommended depth and at two sites the depth was $0 \mathrm{~mm}$.

Five children were injured at five sites falling from rotating structures (figure 3). One contained a single rotating component while the other four play structures comprised multiple units. The minimum recommended CSA standard clearance between such components is $1800 \mathrm{~mm}$, yet all four multiunit structures were well below this minimum, ranging from 248 to $609 \mathrm{~mm}$ of clearance. Two did not have a speed-limiting device. The children who were injured playing on these most often reported that they fell after knocking into another child on the adjacent rotating component.

The remaining structures were varied, including slides $(n=2)$, climbing structures $(n=2)$, unclassified structures 
Table 1 Case summary of child and site characteristics by play structure type

\begin{tabular}{|c|c|c|c|c|c|}
\hline & All $(n=47)$ & Upper body (n=26) & Track ride $(n=7)$ & Rotating structure $(n=5)$ & Other $(n=9)$ \\
\hline \multicolumn{6}{|l|}{ Gender } \\
\hline Males & 29 & 14 & 4 & 3 & 8 \\
\hline Females & 18 & 12 & 3 & 2 & 1 \\
\hline Mean child age & 7 & 7.0 & 6.9 & 6.4 & 7.5 \\
\hline \multicolumn{6}{|l|}{ Injury severity } \\
\hline Type 1 & 14 & 12 & 1 & - & 1 \\
\hline Type 2 & 23 & 11 & 4 & 3 & 5 \\
\hline Type 3 & 10 & 3 & 2 & 2 & 3 \\
\hline \multicolumn{6}{|l|}{ Surgery performed } \\
\hline Yes & 15 & 6 & 3 & 2 & 4 \\
\hline No & 32 & 20 & 4 & 3 & 5 \\
\hline \multicolumn{6}{|l|}{ Surface type } \\
\hline EWF & 42 & 23 & 7 & 5 & 7 \\
\hline Other & 5 & 3 & - & - & 2 \\
\hline \multicolumn{6}{|l|}{ Surface depth } \\
\hline $300 \mathrm{~mm}$ or more & 7 & 1 & - & 2 & 4 \\
\hline$<300 \mathrm{~mm}$ & 35 & 22 & 7 & 3 & 3 \\
\hline Not applicable & 4 & 2 & - & - & 2 \\
\hline No data & 1 & 1 & - & - & - \\
\hline \multicolumn{6}{|l|}{ Fall height } \\
\hline$>2000 \mathrm{~mm}$ & 27 & 17 & 5 & 4 & 1 \\
\hline $2000 \mathrm{~mm}$ or less & 18 & 9 & 2 & 1 & 6 \\
\hline Undetermined & 2 & - & - & - & 2 \\
\hline
\end{tabular}

EWF, engineered wood fibre.

$(n=2)$, pyramid $(n=1)$, swing $(n=1)$ and sandbox $(n=1)$. The children who were injured at these sites most commonly climbed partway up the structures before falling, with the exception of one child who jumped from the top bar of a climbing structure, one who tripped over the side of the sandbox and one who fell from a swing at an undermined height.

\section{DISCUSSION}

While falls from playground equipment, particularly monkey bars, are a common cause of SCHF among children, ${ }^{34}$ this study found that in all but two cases, children presenting to the emergency department with SCHF sustained at a public playground fell onto surfaces with

\begin{tabular}{|c|c|c|c|c|c|}
\hline Equipment & Measurement & $\begin{array}{l}\text { Standard } \\
\text { met }\end{array}$ & $\begin{array}{l}\text { Standard not } \\
\text { met }\end{array}$ & $\begin{array}{l}\text { Not } \\
\text { applicable }\end{array}$ & $\begin{array}{l}\text { No } \\
\text { data }\end{array}$ \\
\hline \multirow[t]{5}{*}{ Upper body } & Centre-to-centre distance between fixed rungs ( $\max 375 \mathrm{~mm}$ ) & 11 & 11 & 2 & 2 \\
\hline & Handgrip devices diameter (20-40 mm) & 24 & 1 & - & 1 \\
\hline & Horizontal distance between platform and handle (200-250 mm) & 6 & 16 & 2 & 2 \\
\hline & Height of handle for $5-12$ years ( $\max 2100 \mathrm{~mm}$ ) & 15 & 11 & - & - \\
\hline & Platform height for $5-12$ years (max $900 \mathrm{~mm}$ ) & 20 & 1 & 2 & 3 \\
\hline \multirow[t]{4}{*}{ Track ride } & Height of track ride (1600-1950 mm) & 1 & 6 & - & - \\
\hline & Platform height for $5-12$ years (max $900 \mathrm{~mm}$ ) & 7 & - & - & - \\
\hline & Riding zone clearance (min 900 mm) & 3 & 4 & - & - \\
\hline & Protective surfacing zone extending to all directions (min $1800 \mathrm{~mm}$ ) & 5 & 2 & - & - \\
\hline \multirow{2}{*}{$\begin{array}{l}\text { Rotating } \\
\text { structure }\end{array}$} & Distance between components ( $\min 1800 \mathrm{~mm}$ ) & - & 4 & 1 & - \\
\hline & $\begin{array}{l}\text { Height of handle for } 5-12 \text { years ( } \max 2100 \mathrm{~mm} \text { ) } \\
\text { (from upper body standards, no standard under rotating) }\end{array}$ & 2 & 3 & - & - \\
\hline
\end{tabular}

CSA, Canadian Standards Association. 


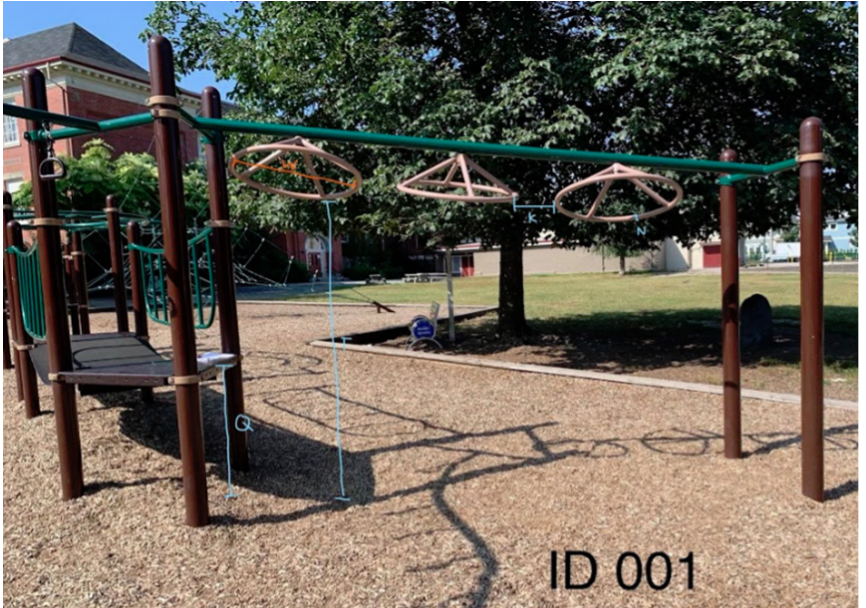

Figure 3 Example of rotating structure.

depths below those recommended by the CSA. These findings are consistent with other studies of playground SCHF in Australia and Canada showing that surface depths of loose fill materials, including EWF, were most often well below the recommended maintenance threshold. ${ }^{17} 18$

The most common structure from which children fell came under the CSA classification of upper body, followed by track lines and rotating structures. Notably, all rotating structures with multiple components had far below the minimum standard clearance between the components, and children injured when playing on these most often fell because they collided with another child on an adjacent component. The frequency with which children appear to be injured on these structures suggests that they may be the most popular structures in the playground and their appeal can be understood in the context of risky play. Structures such as monkey bars and track lines offer the chance to experience great heights and great speed, two elements that partly define thrilling play and provide opportunities for children to test their own abilities to cope with uncertainty and challenge. ${ }^{1920}$ Sandseter and Kennair argue that exposure to adaptive and universal fears, such as the fear of falling, through risky play experiences provides children with essential opportunities to learn coping skills and develop their self-confidence. ${ }^{2}$ Perhaps these structures are more challenging for children, which increases their appeal, but the inherent risk also increases the chance children will sustain an injury if they misjudge distance, get tired, slip, or lose balance and subsequently fall.

Setting and enforcing playground standards that eliminate all possibility of injury is not possible nor desirable, as such an approach limits children's opportunities for risky play and the concomitant benefits, including physical activity, mental health and risk management skills. ${ }^{1}$ Research has shown that quality of life following an injury returns to baseline for most children over the long term, and therefore opportunities to engage in risky play must not be limited by fear of injury. ${ }^{21}$ Because risky play carries an inherent risk of injury, expert consensus is that effective injury prevention in the playground setting must differentiate between opportunities to take risks, of which children are aware and actively seek, and exposure to hazards, of which they are not aware and from which they cannot derive any benefit. ${ }^{22}$ The risk-benefit assessment approach, when combined with safety standards, covers both the engineering and the behavioural aspects of children's play. ${ }^{1223}$

In the present study, the most common measures that did not align with CSA standards, when specified, were the height from which children fell and the depth of surfacing onto which they fell. Most equipment height measurements were close to the relevant standard, which suggests that the equipment was likely compliant when installed and that displacement, erosion and/or compaction of the EWF surfacing over time may have falsely increased height at the time of the child's injurious fall. Although CSA standards do not always specify a maximum height for playground structures, previous research has suggested that the risk of injury is greater when falling from a height of $2 \mathrm{~m}$ or more. ${ }^{9}$ Equipment heights, when specified in the CSA standards, are close to this guideline (see table 2 for examples). In seven cases, increasing the surface depth to at least $300 \mathrm{~mm}$ would still not have made up the difference in height above 2 $\mathrm{m}$, but the average equipment height above $2 \mathrm{~m}$ in this hypothetical scenario would have been less than $5 \mathrm{~cm}$ (average was $47 \mathrm{~mm}$, range from 5 to $99 \mathrm{~mm}$ ). Therefore, it is less likely that fall height was a significant contributor to injury in cases where the child fell from heights that were close to $2 \mathrm{~m}$. Fall height may instead reflect a loss or insufficiency of surfacing depth.

EWF is a popular choice of surface materials for public playgrounds, but its protective value varies considerably between studies for a variety of reasons, including the condition of the surfacing or standard compliance of the play equipment. ${ }^{24-26}$ A study of woodchip (EWF) surfacing in Victoria, Australia, showed that depth measurements deteriorated with time in undisturbed samples, and those exposed to outdoor weather conditions decreased faster than those indoors. ${ }^{23}$ The authors subsequently recommended that woodchip surfacing used in outdoor playgrounds should be groomed every 3 months to maintain the consistent depth. Assuming that the playgrounds included in the present study were initially filled to at least $300 \mathrm{~mm}$, compaction or degradation of the surface material may not entirely account for the loss in depth. However, the research assistants also noted that there was displacement of the surfacing material under many of the play structures, particularly in areas where children would be jumping from the structure to the ground, such as under monkey bars or track rides, or below landing platforms. The observations of surface depth in the present study would suggest that the EWF surfacing in these outdoor public playgrounds deteriorates at a faster rate than might be expected in an indoor playground, particularly under the more popular 
play structures, and/or that they are not maintained as frequently as needed.

The results of this study can assist play providers, school boards and municipalities in decisions that shape children's play spaces with insight into the hazards, rather than the risks, that expose children to fall injuries during play. Encouraging children to play outside is necessary for their physical and mental health, as well as their psychosocial development. The Canadian Paediatric Society guidelines recommend $60 \mathrm{~min}$ or more per day of moderate to vigorous physical activity for school-age children to reduce the health risks of sedentary behaviours and screen time. ${ }^{27}{ }^{28}$ Ensuring that challenging elements are included in play opportunities is crucial for maximally engaging children in outdoor physical activity. The results of this study, therefore, are not intended to encourage decision makers to lower equipment heights, but to prioritise maintaining the chosen surface material to a safe level, ideally defined by impact attenuation testing, that is more likely to reduce exposure to a common hazard. The quality of children's play experiences must not be sacrificed to eliminate the risk of injury, but an evidence-based assessment of hazard mitigation strategies can ensure that play spaces continue to promote children's health and well-being. ${ }^{12}$

This study has some limitations. The sample size was limited to SCHF that occurred in public play spaces and the numbers of cases relating to structures other than upper body structures are small and should be interpreted with some caution (see table 1). The high proportion of injuries attributed to monkey bar falls or similar, relative to other types of equipment, such as slides or swings, observed in this subset is consistent with other studies of playground injuries. ${ }^{29}{ }^{30}$ This study does not include information about exposure rates-that is, the number of children playing on these structures and the time they spent playing to allow calculation of injury incidence rates per hour of exposure. Evidence indicates that serious injuries on playgrounds are rare and that the incidence of medically treated per 1000 hours of activity is lower for play-related injuries than sports. ${ }^{731}$ Recruitment of participants was limited to children who attended BC Children's Hospital for treatment, which likely represents the most severe cases in the region. It was not always possible to determine exactly where the child fell, or to take the measurements immediately afterwards, so it is possible that the surface condition changed between injury occurrence and surface measurement. A strength of this study was that we were able to pinpoint in most cases not just the location but exactly where the child fell to take measurements and relate them to the dimensions of the equipment and the severity of the injury.

\section{CONCLUSION}

The majority of SCHF cases occurred at playgrounds with insufficient surface depth and/or CSA non-compliant equipment. Upper body equipment, track rides and rotating play structures were of particular concern, as the children fell from heights over $2 \mathrm{~m}$, likely reflecting some loss of the surfacing material over time.

Field investigation into the characteristics of playgrounds at which children sustain SCHF can guide preventative policy and practice measures. Municipalities and school boards can be alerted to the need for regular maintenance of EWF playground surfacing to prevent serious injuries, and cautioned to assess height and clearance recommendations when purchasing and installing equipment.

\section{Twitter Pardeep Sidhu @SidhuMed}

Acknowledgements The authors would like to acknowledge the contribution of Atousa Zargaran, BC Children's Hospital site coordinator, Canadian Hospital Injury Reporting and Prevention Program in identifying additional geographic sites of injury. We would also like to acknowledge the support from Mr Damian Duffy, Executive Director, The Office of Pediatric Surgical Evaluation and Innovation at BC Children's Hospital for supporting this project through the summer student programme.

Contributors AC, IP, MB and HC designed the study, and developed and wrote the grant proposal. JS, HC and PS gathered and analysed the data. AC and IP supervised the study and monitored the data collection. JS and HC wrote the initial draft of the manuscript. IP and AC accept full responsibility for the work, have access to the data, and controlled the decision to publish. All authors revised the draft and approved the final manuscript.

Funding This project was partly supported by the summer student funding from the BC Children's Hospital Research Institute (BCCHR). The senior author is supported by the BCCHR Investigator Grant Award Program and research funding from BC Children's Hospital Foundation. MB is supported by the BCCHR Investigator Grant Award Program.

\section{Competing interests None declared.}

Patient and public involvement Patients and/or the public were not involved in the design, or conduct, or reporting, or dissemination plans of this research.

\section{Patient consent for publication Not required.}

Ethics approval This study was reviewed and approved by the BC Children's and Women's Hospital Research Ethics Board (H17-00561).

Provenance and peer review Not commissioned; externally peer reviewed. Data availability statement № data are available.

Open access This is an open access article distributed in accordance with the Creative Commons Attribution Non Commercial (CC BY-NC 4.0) license, which permits others to distribute, remix, adapt, build upon this work non-commercially, and license their derivative works on different terms, provided the original work is properly cited, appropriate credit is given, any changes made indicated, and the use is non-commercial. See: http://creativecommons.org/licenses/by-nc/4.0/.

\section{ORCID iDs}

Jennifer Smith http://orcid.org/0000-0001-6428-7694

Harpreet Chhina http://orcid.org/000000027656457X

Pardeep Sidhu http://orcid.org/0000-0002-3866-0843

Mariana Brussoni http://orcid.org/000000021495816X

lan Pike http://orcid.org/000000268607760

Anthony Cooper http://orcid.org/0000000278642981

\section{REFERENCES}

1 Brussoni M, Gibbons R, Gray C, et al. What is the relationship between risky outdoor play and health in children? A systematic review. Int J Environ Res Public Health 2015;12:6423-54.

2 Sandseter EBH, Kennair LEO. Children's risky play from an evolutionary perspective: the anti-phobic effects of thrilling experiences. Evol Psychol 2011;9:147470491100900-284.

3 Adelson SL, Chounthirath T, Hodges NL, et al. Pediatric PlaygroundRelated injuries treated in hospital emergency departments in the United States. Clin Pediatr 2018;57:584-92. 
4 McRae B, Nusem I. Temporal characteristics of paediatric supracondylar humerus fractures. Trauma 2018;20:208-16.

5 Canadian Hospitals Injury Research and Prevention Progam, British Columbia Children's Hospital. Public health agency of Canada, Ottawa, Ontario. injury data online tool (iDOT), bc injury research and prevention unit, 2018. Available: https://www.injuryresearch.bc.ca/ idot/injury-er-visits-bc-childrens/ [Accessed 20 Dec 2020].

6 Discharge Abstract Database (DAD), Ministry of Health. Injury data online tool (iDOT), bc injury research and prevention unit, 2018. Available: https://www.injuryresearch.bc.ca/idot/injuryhospitalizations/ [Accessed 20 Dec 2020].

7 Bergeron N, Bergeron C, Lapointe L, et al. Don't take down the monkey bars: Rapid systematic review of playground-related injuries. Can Fam Physician 2019;65:e121-8.

8 Tan SHS, Dartnell J, Lim AKS, et al. Paediatric lateral condyle fractures: a systematic review. Arch Orthop Trauma Surg 2018;138:809-17.

9 Laforest S, Robitaille Y, Lesage D, et al. Surface characteristics, equipment height, and the occurrence and severity of playground injuries. Inj Prev 2001;7:35-40.

10 Howard AW, MacArthur C, Willan A, et al. The effect of safer play equipment on playground injury rates among school children. CMAJ 2005;172:1443-6.

11 Herrington S, Nicholls J. Outdoor play spaces in Canada: the safety dance of standards as policy. Crit Soc Policy 2007;27:128-38.

12 Ball DJ, Brussoni M, Gill TR, et al. Avoiding a dystopian future for children's play. Int J Play 2019;8:3-10.

13 Macpherson AK, Jones J, Rothman L, et al. Safety standards and socioeconomic disparities in school playground injuries: a retrospective cohort study. BMC Public Health 2010;10:542.

14 Lim BT, Chhina H, Pike I, et al. Methodological challenges in investigating supracondylar fractures of the humerus from a child's viewpoint: evolution of study protocol. JMIR Res Protoc 2020;9:e21816.

15 CSA Group. Children's Playspaces and Equipment. CAN/CSA-Z6. Toronto, Ontario: Canadian Standards Association, 2014

16 Kumar V, Singh A. Fracture supracondylar humerus: a review. J Clin Diagn Res 2016;10:1-6.

17 Sherker S, Ozanne-Smith J. Are current playground safety standards adequate for preventing arm fractures? Med J Aust 2004;180:562-5.

18 Macarthur C, Hu X, Wesson DE, et al. Risk factors for severe injuries associated with falls from playground equipment. Accid Anal Prev 2000;32:377-82.
19 Leeper CM, McKenna C, Gaines BA. Homemade zipline and playground track ride injuries in children. $J$ Pediatr Surg 2017;52:1511-5.

20 Hansen Sandseter EB. Categorising risky play-how can we identify risk-taking in children's play? Eur Early Child Educ Res $J$ 2007;15:237-52.

21 Schneeberg A, Ishikawa T, Kruse S, et al. A longitudinal study on quality of life after injury in children. Health Qual Life Outcomes 2016;14:1-11.

22 Brussoni M, Brunelle S, Pike I, et al. Can child injury prevention include healthy risk promotion? Inj Prev 2015;21:10.1136/injuryprev2014-041241:344-7.

23 Sherker S, Short A, Ozanne-Smith J. The in situ performance of playground surfacing: implications for maintenance and injury prevention. Int $\mathrm{J}$ Inj Contr Saf Promot 2005;12:10.1080/17457300512331339184:63-6.

24 Howard AW, Macarthur C, Rothman L, et al. School playground surfacing and arm fractures in children: a cluster randomized trial comparing sand to wood CHIP surfaces. PLoS Med 2009;6:e1000195.

25 Mott A, Rolfe K, James R, et al. Safety of surfaces and equipment for children in playgrounds. Lancet 1997;349:10.1016/S01406736(96)10343-3:1874-6.

26 East D, Gustafson K, Cabaj J, et al. An assessment of child care facility playground surfacing safety in Calgary, Alberta. Environ Health Rev 2018;61:19-11.

27 Canadian Paediatric Society. Healthy active living: physical activity guidelines for children and adolescents, 2012. Available: https:// www.cps.ca/en/documents/position/physical-activity-guidelines [Accessed 28 Sep 2020]

28 Pan-Canadian Public Health Network. Active outdoor play statement from the Council of chief medical officers of health, 2018. Available: http://www.phn-rsp.ca/aop-position-jae/index-eng.php [Accessed 10 Apr 2021].

29 Tuckel P, Milczarski W, Silverman DG. Injuries caused by falls from playground equipment in the United States. Clin Pediatr 2018:57:563-73.

30 Nixon JW, Acton $\mathrm{CHC}$, Wallis B, et al. Injury and frequency of use of playground equipment in public schools and Parks in Brisbane, Australia. Inj Prev 2003;9:210-3.

31 Nauta J, Martin-Diener E, Martin BW, et al. Injury risk during different physical activity behaviours in children: a systematic review with bias assessment. Sports Med 2015;45:327-36. 